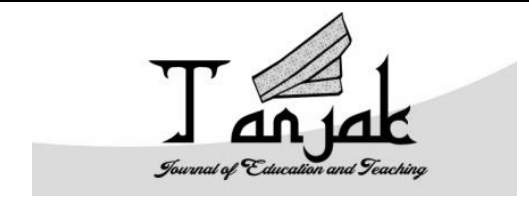

Tanjak: Journal of Education and Teaching

ISSN 2716-4098 (P) 2720-8966 (O)

Volume 2 Nomor 1, 2021

\title{
PENGARUH KEADAAN SOSIAL EKONOMI ORANG TUA TERHADAP HASIL BELAJAR DI TAMAN PENDIDIKAN AL-QUR'AN BAITUL MUTTAQIN TOAPAYA UTARA DI ERA NEW NORMAL
}

\author{
Kamaruzaman $^{1}$, Sudanto $^{2}$, Devira Aulia Bidari ${ }^{3}$, Meti Febriana ${ }^{4}$, Nufikha $^{5}$
}

STAIN Sultan Abdurrahman Kepulauan Riau, Bintan, Kepulauan Riau 29151, Indonesia

DOI: https://doi.org/10.31629/ig.v2i1.245

\begin{abstract}
Abstrak
Penelitian ini dilakukan karena munculnya pandemi COVID-19. Dimana hal tersebut menghambat banyak kegiatan sehari-hari. Salah satunya kegiatan perekonomian dan pendidikan. Dengan tujuan dpat memcahkan dan mencari solusi terkait pengaruh keadaan social ekonomi orang tua terhadap hasil belajar di Taman Pendidikan AlQur'an Baitu Muttaqin Toapaya Utara di era new normal. Populasi dan sampel berdasarkan sumber data dari Taman Pendidikan Al-Qur'an Baitul Muttaqin tahun 2020 berjumlah 54 orang. Dalam penelitian ini menggunakan penelitian kualitatif dengan sumber data menggunakan data primer adalah hasil wawancara terhadap orang tua, santri dan tenaga pengajar. Dan data sekunder yang digunakan adalah referensi data peserta didik Taman Pendidikan Al-Qur'an Baitul Muttaqin, Literatur Artikel, data dari internet serta dokumen lainya. Dengan menggunkana teknik pengumpulan data metode documenter yaitu berupa catatan atau dokumen yang berasal dari Taman Pendidikan Al-Qur'an Baitul Muttaqin. Dengan menggunakan teknik analisis data dengan menggunakan pendekatan kualitatif, yaitu prosedur penelitian yang menghasilkan data deskriptif berupa kata-kata tertulis atau lisan berdasarkan orang atau perilaku yang diamati. Berdasarkan hasil penelitian, mayoritas kelompok ekonomi orang tua siswa Taman Pendidikan Al-Qur'an Baitul Muttaqin adalah kelas menengah. Hubungan anak dengan orang tuanya mempunyai pengaruh dalam perkembangan si anak serta pengaruh tersebut sangat kuat antara kondisi sosial ekonomi dengan hasil belajar santri.
\end{abstract}

Kata kunci: Keadaan Ekonomi, Hasil Belajar, TPQ

Tanjak: Jounal of Education and Teaching, Vol. 2, No. 1, 2021 


\title{
Kamaruzaman, Sudanto, Devira Aulia Bidari, Meti Febriana, Nufikha
}

\begin{abstract}
This research was conducted because of the emergence of the COVID-19 epidemic. Where it hinders many daily activities. One of them is economic and educational activities. With the aim of being able to solve and find solutions related to the influence of parents' socio-economic conditions on learning outcomes at the Al-Qur'an Baitu Education Park, Muttaqin Toapaya Utara in the new normal era. Population and sample based on data sources from the Al-Qur'an Baitul Muttaqin Education Park in 2020 amounted to 54 people. In this study using qualitative research with data sources using primary data is the results of interviews with parents, students and teaching staff. And secondary data used is reference data from students of Al-Qur'an Education Park Baitul Muttaqin, Article Literature, data from the internet and other documents. By using the documentary method data collection technique, namely in the form of notes or documents from the Al-Qur'an Education Park Baitul Muttaqin. By using data analysis techniques using a qualitative approach, namely research procedures that produce descriptive data in the form of written or spoken words based on the person or behavior observed. Based on the results of the study, the majority of the economic group of the students of the Baitul Muttaqin Al-Qur'an Education Park were middle class. The relationship between children and their parents has an influence on the development of the child and this influence is very strong between the socio-economic conditions and the learning outcomes of the students.
\end{abstract}

Keywords: Economic Situation, Study Achievement and TPQ

\section{Pendahuluan}

Pendidikan merupakan elemen penting dalam meningkatkan kualitas kehidupan manusia dan perkembangan sosial maupun ekonomi. Keberhasilan pembangunan kaitannya tidak hanya dari elemen ekonomi, akan tetapi menitikberatkan pada kualitas sumber daya manusia. Pendidikan adalah usaha sadar dan terencana untuk mewujudkan suasana belajar dan proses pembelajaran agar peserta didik secara aktif mengembangkan potensi dirinya untuk memiliki kekuatan spiritual keagamaan, pengendalian diri, kepribadian, kecerdasan, akhlak mulia, serta keterampilan yang diperlukan dirinya, masyarakat bangsa dan Negara (Undang-Undang Republik Indonesia Nomor 20 Tahun 2003). Data BPS Bintan menyebutkan jumlah sekolah dasar (SD) di Kecamatan Toapaya berjumlah 6 sekolah yang akan menjadi murid/santri di TPA di Kecamatan Toapaya (Badan Pusat Statistik Kabupaten Bintan 2021).

Hasil belajar merupakan kemampuan yang dimiliki oleh peserta didik setelah mendapatkan pengalaman pembelajaran. Hasil belajar mempunyai peranan penting dalam proses pembelajaran. Tujuan utama yang dicapai dalam kegiatan pembelajaran adalah hasil belajar yang diperoleh siswa setelah melakukan kegiatan belajar dan pembelajaran serta bukti keberhasilan yang telah dicapai dengan melibatkan aspek kognitif, afektif maupun psikomotor yang dinyatakan dalam simbol, huruf maupun kalimat. Hasil belajar sebagai tingkat penguasaan yang dicapai oleh pelajar dalam mengikuti proses belajar mengajar sesuai dengan tujuan pendidikan yang ditetapkan (Hisyam 2018).

Kondisi sosial ekonomi orang tua merupakan salah satu faktor eksternal yang dapat mempengaruhi hasil belajar siswa. Keadaan sosial ekonomi keluarga mempunyai peranan terhadap perkembangan anak, misalnya keluarga yang perekonomiannya cukup menyebabkan lingkungan materil yang dihadapi oleh anak didalam keluarganya lebih luas permasalahan sosial ekonomi keluarga yang

Tanjak: Jounal of Education and Teaching, Vol. 2, No. 1, 2021 
utama adalah usaha keluarga untuk dapat memenuhi kebutuhan sehingga mencapai kemakmuran (Febriana 2014).

Kebutuhan yang dimaksud adalah kebutuhan jasmani (material) dan kebutuhan rokhani (spiritual). Pemenuhan tersebut harus dilakukan dalam keadaaan sumber-sumber yang dimiliki terbatas dihadapkan dengan kebutuhan yang alternatif. Kondisi sosial ekonomi orang tua dalam kehidupan sehari-hari tergantung pada dua hal yang saling berhubungan, yaitu adanya kebutuhan keluarga yang tidak terbatas, baik jumlah maupun kualitasnya, dan jumlah sumber-sumber yang dimiliki untuk memenuhi kebutuhan tersebut (pendapatan) (Chlarantika 2017).

Dengan munculnya wabah pandemi COVID-19 kegiatan sehari-hari sangat terganggu, dari segala aspek baik akademik maupun ekonomi. Kegiatan belajar mengajar sempat diliburkan dua minggu diawal munculnya COVID-19, tetapi karena tahu tidak akan reda dalam waktu singkat maka kegiatan belajar mengajar di alihkan menjadi dalam jaringan. Dan juga kegiatan ekonomi mengalami penurunan, di awal masa pandemi COVID-19 pemerintah sempat membuat surat edaran untuk membatasi kegiatan ekonomi yang melibatkan keramaian dan kegiatan tatap muka (Syah, Utari, and Adinugraha 2020).

Hal tersebut dilakukakn dilakukan dalam jangka waktu yang tidak ditentukan, melihat kondisi tersebut tidak akan berakhir dalam waktu deket pemerintah menetapkan peraturan baru, yaitu era new normal. Dimana kegiatan sehari-hari dapat dilakukan dengan peraturan baru yang telah ditetapkan, seperti menerapkan protocol kesehatan dan jaga jarak. Tujuan dari penilitian ini adalah untuk dapat mengetahui pengaruh keadaan social ekonomi orang tua terhadap hasil belajar santri di Taman Pendidikan Al-Qur'an Toapaya Utara di Era New Normal.

\section{Metode Penelitian}

Dalam penelitian ini, metode yang digunakan adalah deskritif kualitatif. Metode deskriftif ini merupakan suatu metode yang dilaksanakan dalam penelitian dengan tujuan untuk menggambarkan atau menganalisis suatu hasil penelitian namun untuk menarik kesimpulan yang lebih komprehensif. Lokasi penelitian ini dilakukan di Desa Toapaya Utara, Kecamatan Toapaya, Kabupaten Bintan, Provinsi Kepulauan Riau di Taman Pendidikan Al-Quran (TPA/TPQ) Baitul Muttaqin. Populasi dalam penelitian ini berdasarkan sumber data dari TPQ Baitul Muttaqin tahun 2020 adalah seluruh Santri TPQ Baitul Muttaqin pada tahun 2020 berjumlah 54 orang dari umur 5-15 tahun. Metode penentuan sampel dan penelitian ini menggunakan metode Simple Random Sampling, dimana pengambilan sample diambil secara acak diantara bebearapa santri TPQ Baitu Muttaqin. Dalam penelitian ini menggunakan penelitian kualitatif dengan sumber data menggunakan data primer dalam penelitian ini adalah data hasil wawancara terhadap Santri, Orang Tua dan Tenaga Pengajar terkait pengaruh keadaan sosial ekonomi orang tua terhadap hasil belajar santri di masa era new normal. Dalam penelitian ini juga menggunakan data sekunder yang digunakan adalah referensi data Peserta Didik TPQ Baitul Muttaqin, Literatur Artikel, Data dari Internet serta dokumen lainnya. Teknik pengumpulan data dalam penelitan ini yaitu peneliti melakukan metode dokumenter yaitu berupa catatan atau dokumen yang tersedia berasal dari TPQ Baitul Muttaqin seperti Biodata tenaga pengajar, Biodata Santri, Laporan Bulanan TPQ Baitul

Tanjak: Jounal of Education and Teaching, Vol. 2, No. 1, 2021 
Muttaqin dan Data sarana dan prasarana. Selain itu juga untuk mendapatkan data yang akurat kami melakukan teknik wawancara kepada Santri, Orag Tua dan Tenaga Pengajar dengan mengajukan beberapa pertanyaan kepada informan. Teknik analisis data dalam penelitian ini adalah menggunakan penelitian dengan pendekatan kualitatif yaitu suatu prosedur penelitian yang menghasilkan data deskriptif berupa kata-kata tertulis atau lisan berdasarkan orang atau perilaku yang diamati (Ruli 2020).

\section{Hasil dan Pembahasan}

\section{Gambaran Umum Kondisi Sosial Ekonomi Orang Tua Santri Taman Pendidikan Al-Qur'an Kepulauan Riau}

Dalam suatu penelitian merumuskan bahwa golongan sosial ekonomi terdiri dari golongan tinggi, menengah dan rendah. Dapat diketahui dari penggolongan tersebut bahwa sudah sejak lama diakui pembagian tingkatan golongan sosial-ekonomi masyarakat terbagi menurut pendapatan, kepemilikan terhadap kebendaan yang bernilai apakah berbentuk uang, barang-barang berharga/bernilai ekonomi tinggi, tanah, dan maupun hal yang bersifat tidak berwujud namun bernilai kepuasan tinggi seperti kekuasaan maupun tingkat Pendidikan/penguasaan ilmu pengetahuan (Santi 2009).

Kondisi sosial ekonomi orang tua adalah kedudukan atau posisi orang tua yang ditentukan oleh tingkat pendidikan, tingkat pendapatan, tingkat pekerjaan, dan sebagainya. Disertai dengan kemampuan orang tua dalam memenuhi segala kebutuhan keluarga sehari-hari, termasuk kemampuan orang tua dalam membiayai dan menyediakan fasilitas belajar anak sebagai bentuk tanggung jawab mereka terhadap anak-anaknya. Dengan demikian, hal tersebut mempengaruhi tingkat sosial ekonomi masyarakat yang juga menentukan tinggi rendahnya status seseorang dalam masyarakat. Jenis pekerjaan orang tua tentunya mempengaruhi hasil belajar siswa, ini dilihat dari segi waktu yang diluangkan oleh orang tua kepada anaknya. Orang tua yang bekerja sebagai pegawai tentunya akan lebih banyak meluangkan waktunya untuk memberikan bimbingan kepada anak, sedangkan orang tua yang bukan pegawai cenderung akan lebih banyak menghabiskan waktunya untuk bekerja.

Manusia sebagai makhluk hidup memiliki berbagai macam kebutuhan, baik kebutuhan psikologis maupun kebutuhan fisik, untuk memenuhi kebutuhan tersebut manusia harus melakukan suatu kegiatan yaitu yang bisa disebut dengan bekerja, dengan bekerja seseorang akan memperoleh penghasilan. Dalam KBBI menyebutkan bahwa pekerjaan adalah aspek kebendaan apa yang dapat diperbuat dan dipekerjakan dan lain sebagainya; Kewajiban/Tugas; Pedapatan dari bekerja; Perbuatan; dan mata pencaharian yang merupakan sumber utama penghidupan; Sesuatu yang digunakan untuk memberi nafkah; Atau sesuatu yang sedang berproses kerja. Status social juga menjadi parameter yang diperoleh dari pekerjaan. Masyarakat memandang bahwa terdapat pekerjaan-pekerjaan tertentu yang menjadi suatu prestasi sehingga membawanya kepada peningkatan kelas sosial atas dan bahkan sebaliknya menurunkan kelas sosialnya (Hisyam 2018).

Dari hasil wawancara informan terhadap pengaruh social ekonomi, kami simpulkan bahwa mayoritas orang tua santri Taman Pendidikan Al-Qur'an Baitul Muttaqin golong ekonomi menengah.

Tanjak: Jounal of Education and Teaching, Vol. 2, No. 1, 2021 
Berikut merupakan presentase golongan ekonomi orang tua santri Taman Pendidikan Al-Qur'an Baitul Muttaqin Toapaya Utara. Adapun gambaran golongan ekonomi orang tua santri TPQ Baitul Muttaqin dapat dilihat pada gambar berikut ini:

\section{Golongan Ekonomi Orang Tua Santri TPQ Baitul Muttaqin}

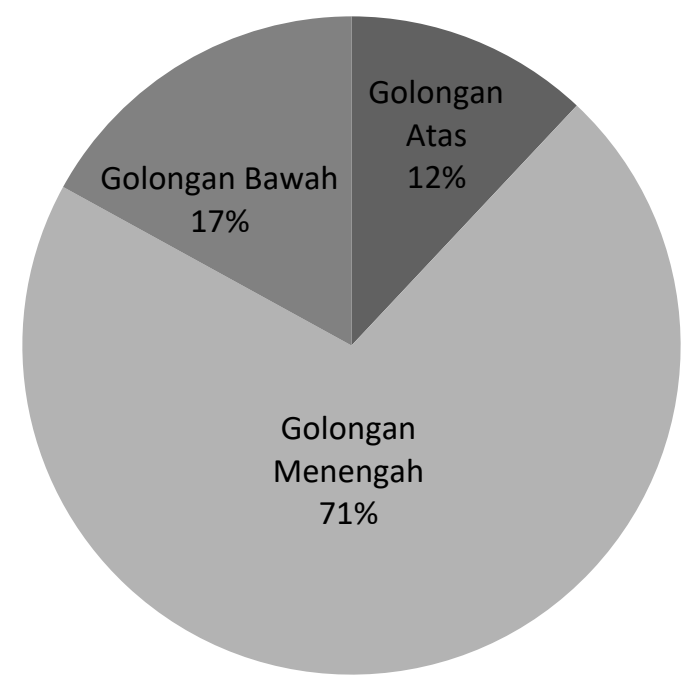

Gambar 1. Golongan Ekonomi Orang Tua Santri TPQ Baitul Muttaqin

Dari diagram diatas menunjukkan Golongan Ekonomi Orang Tua Santri TPQ Baitul Muttaqin Toapaya Utara. Ada 3 golongan ekonomi orang tuan santri: pertama Golongan bawah yaitu sebanyak $17 \%$ dari total orang tuan santri. Kedua Golongan Menengah yaitu sebanyak $71 \%$ dari total orang ruan santri dan Ketiga Golongan Atas yaitu sebanyak 12\% dari total keseluruhan orang tua santri. Artinya golongan yang terbanyak adalah golongan ekonomi menengah.

\section{Pengaruh Kondisi Sosial Ekonomi Orang Tua Terhadap Hasil Belajar di Era New Normal}

Peranan keluarga khususnya orang tua akan sangat menentukan besarnya pengaruh proses pendidikan anak di lingkungan keluarga, dan pada akhirnya akan mempengaruhi hasil belajar. Untuk mencapai keberhasilan belajar tidak hanya dari lingkungan keluarga saja, namun juga banyak sekali faktor yang mempengaruhi. Seperti halnya kemampuan dasar santri, dorongan dari dalam diri santri,

Tanjak: Jounal of Education and Teaching, Vol. 2, No. 1, 2021

http://ejournal.stainkepri.ac.id/index.php/tanjak 
kondisi orang tua dan lain sebagainya. Untuk mencapai keberhasilan tersebut ada berbagai faktor yang saling berhubungan antara satu sama lain.

Keluarga dengan pendapatan yang cukup tinggi pada umumnya akan lebih mudah memenuhi segala kebutuhan dan keperluan hidup. Berbeda dengan keluarga yang mempunyai penghasilan relatif rendah, pada akan umumnya mengalami kesulitan dalam pembiayaan dan keperluan lainnya.

Tingkat kesadaran sebagian orang tua untuk mendorong anaknya agar belajar masih kurang karena faktor ekonomi yang rendah, bahkan beberapa orang tua merasa keberatan dalam pembayaran SPP. SPP tersebut perbulan sebesar Rp. 10.000,00. Namun dalam keadaan COVID- 19 pembayaran tersebut di berhentikan selama setahun dari bulan Maret hingga bulan Desember 2020, karena banyaknya santri di rumahkan dan belajar dirumah masing - masing. Berdasarkan paparan tersebut, peneliti berasumsi bahwa kondisi social ekonomi orang tua sangat mempengaruhi perkembangan hasil belajar santri.

\section{Alternatif Pengajar di Era New Normal}

Dalam metode pembelajaran di masa COVID-19 salah satu hal yang menjadi tantangan utama adalah mengenai tenaga pengajar. Dikarenakan kegiatan tatap muka dengan masa yang banyak harus dibatasi. Tenaga pengajar memberikan alternatif dengan melakukan pembelajaran dirumah pribadi tenaga pengajar dengan pembagian jadwal yang sudah ditentukan. Kegiatan belajar dibagi menjadi dua kelompok dan diberi libur pada hari senin. Maka pada Era New Normal ini tenaga pengajar kembali membuka pengajaran tatap muka di TPQ Baitul Muttaqin dengan mematuhi protokol kesehatan serta menjaga jarak dan memulai lagi pembayaran SPP pada awal bulan Januari tahun 2021. Namun jika situasi meminta pembelajaran tidak dengan tatap muka, maka pihak TPQ dapat melakukan pembelajaran dengan metode daring. Banyak platform media social dan pembelajaran yang dapat dimanfaatkan untuk mempertahankan penyelengara pendidkan tetap melaksanakan proses belajar mengajar sekalipun dengan jarak jauh. Hasil kegiatan KKN Mahasiswa STAIN Sultan Abdurrahman tahun 2020 telah merumuskan dan menawarkan berbagai pilihan pembelajaran di tengan masa pandemi COVID-19 seperti berbasis Google (Google Suites), berbasis Video Conference seperti ZOOM, GMeet, Aplikasi Kinemaster, dan Aplikasi berbasis Whatsapp dan lain sebagainya (Kamaruzaman et al. 2020).

Selain itu bagi orang tua santri dalam upaya untuk bertahan atau meningkatkan penghasilan ekonomi keluarga, perlu adanya mengikuti proses pembelajaran berbisnis atau berwirausaha agar mampu untuk memepersiapkan diri ditengah keadaan yang sulit akibat dampak pandemi COVID-19 ini. Kemampuan merumuskan usaha secara mandiri juga dibutuhkan pendidikan dan pelatihan perencanaan usaha (business plan). Menurut suatu kajian menemukan bahwa terdapat persepsi yang positif dalam pembelajaran kewirausahaan bagi respondennya setelah dibekali dengan pelatihan penyusunan penyusunan rencana bisnis (Kamaruzaman and Asrizal 2020). Hal ini diperlukan dalam rangka mengantisipasi dampak yang multi efek dari pandemi COVID-19 termasuk hasil belajar santri di TPQ. 


\section{Kesimpulan}

Berdasarkan hasil penelitian yang dilakukan di Taman Pendidikan Al-Qur'an Baitul Muttaqin Toapaya Utara tentang Pengaruh Keadaan Sosial Ekonomi Orang tua terhadap hasil belajar dapat disimpulkan :

1. Terdapat gambaran diagram presentase kondisi golongan ekonomi orang tua santri Taman Pendidikan Al-Qur'an Baitul Muttaqin termasuk dalam kategori menengah/ cukup ( $71 \%$ )

2. Hubungan anak dengan orang tuanya mempunyai pengaruh dalam perkembangan si anak serta pengaruh tersebut sangat kuat antara kondisi sosial ekonomi dengan hasil belajar santri.

3. Pandemi COVID-19 sangat menghambat proses pembelajaran santri karena sebelum diterapkannya Era New Normal para santri melakukan pembelajaran di rumah masing - masing dan pembayaran SPP pun terhentkan selama setahun. Setelah di lakukan nya Era New Normal para santri dapat melakukan pembelajaran dengan tatap muka di TPQ Baitull Muttaqin dengan mematuhi protokol kesehatan serta menjaga jarak dan memulai lagi pembayaran SPP pada awal bulan Januari tahun 2021.

4. Penelitian ini di lakukan pada santri di TPQ Baitul Muttaqin yang berjumlah 54 orang dari umur 515 tahun dan sample diambil secara acak diantara beberapa santri.

\section{Ucapan Terimakasih}

Penulis mengucapkan Terimakasih kepada pihak-pihak terkait yang telah membantu kami dalam penelitian ini. Kepada Orang Tua, Santri dan Tenaga Pengajar Taman Pendidikan Al-Qur'an Baitul Muttaqin. Dan pihak lainya yang tidak dapat kami sebutkan satu persatu.

\section{Referensi}

Badan Pusat Statistik Kabupaten Bintan. 2021. "Kabupaten Bintan Dalam Angka 2021." Handbook of Pediatric Retinal OCT and the Eye-Brain Connection 287.

Chlarantika, Ferdina Destyolentia. 2017. "Pengaruh Kondisi Sosial Ekonomi Orang Tua Dengan Hasil Belajar Siswa Di Sd Negeri Tambak Aji 03 Ngaliyan Kota Semarang." Universitas Negeri Semarang.

Febriana, Sefti Wiri. 2014. "Pengaruh Kondisi Sosial Ekonomi Orang Tua Dan Perhatian Orang Tua Terhadap Prestasi Belajar Ekonomi Pada Siswa Kelas XI IPS SMA Negeri 1 Purwantoro Tahun Ajaran 2013/2014."

Hisyam, Fadian Ra'id. 2018. "Pengaruh Kondisi Sosial Ekonomi Orang Tua Dan Lingkungan Teman Sebaya Terhadap Motivasi Belajar Dan Hasil Belajar Mata Pelajaran Ekonomi Siswa Kelas X IPS Dan XI IPS SMA N 1 Bawang Kabupaten Banjarnegara Tahun Ajaran 2016/2017.”

Kamaruzaman, and Asrizal. 2020. "Persepsi Mahasiswa Non-Bisnis Terhadap Kuliah Kewirausahaan

Tanjak: Jounal of Education and Teaching, Vol. 2, No. 1, 2021 
Pasca Pelatihan Penyusunan Bisnis Plan.” Jurnal Ekonomi Islam AL-AMW AL 9(1):28-37.

Kamaruzaman, Syahrul Ulum, Susi Susilawati, Latifa Hanum Ghultom, Ainul Mutaqhoro, Egi Iskarisma, Maulana Aqlis Azet, M. Sufyan Nur Zuhaili, Sekolah Tinggi, Agama Islam, Negeri Sultan, Kabupaten Bintan, Google Meet, Google Classroom, Video Tutorial, and Manual Book. 2020. "Optimalisasi Kontribusi Melalui Pengembangan Program Kkn-Dari Rumah Bagi Masyarakat." 1.

Ruli, Efrianus. 2020. "Tugas Dan Peran Orang Tua Dalam Mendidk Anak.” Jurnal Edukasi Nonformal 1(2):143-46.

Santi, Sinta Dyana. 2009. "Pengaruh Kondisi Sosial Ekonomi Orang Tua Terhadap Prestasi Belajar Sosiologi Siswa Kelas XII IPS SMA N 1 Karang Tengah Kabupaten Demak Tahun Ajaran 2008/2009."

Syah, Deby Zulkarnain Rahadian, Dewi Utari, and Tetra Saktika Adinugraha. 2020. "Edukasi Penerapan Protokol Kesehatan Penyelenggaraan Kegiatan Pada Masa Pandemi Covid 19 Di Tpq Masjid Awalulmu’Minin Gamping." Jurnal Pengabdian Masyarakat Karya Husada 2(2):28-33.

Undang-Undang Republik Indonesia Nomor 20 Tahun 2003. 2003. Undang-Undang Republik Indonesia Nomor 20 Tahun 2003 Tentang Sistem Pendidikan Nasional.

Tanjak: Jounal of Education and Teaching, Vol. 2, No. 1, 2021 